Volume 6, Issue 1, January 2021, pp. 1 - 16

DOI: $10.23917 /$ jramathedu.v6i1.11898

p-ISSN: 2503-3697, e-ISSN: 2541-2590

\title{
A design approach to mathematics teacher educator development in East Africa
}

\author{
Jennie Golding ${ }^{1 *}$, Marjorie Sarah K. Batiibwe ${ }^{2}$ \\ ${ }^{1}$ Institute of Education, University College London, United Kingdom \\ ${ }^{2}$ Department of Science, Technical and Vocational Education, Makerere University, Kampala, Uganda \\ ${ }^{*}$ Corresponding Author: j.golding@ucl.ac.uk
}

\begin{tabular}{l}
\hline ARTICLE INFO \\
\hline Article history: \\
Received: 18 August 2020 \\
Revised: 30 October 2020 \\
Accepted: 2 November 2020 \\
Published online: 16 \\
December 2020 \\
Published regularly: January \\
2021
\end{tabular}

Keywords:

distance learning, East Africa, mathematics teacher educator, primary mathematics, technology

\begin{abstract}
Mathematical functioning in sub-Saharan Africa remains persistently weak in global terms. This limits the flourishing of young people and communities in the region. Moreover, affordable, effective ways to address the issue are not well established. This paper analyses outcomes from a blended learning 'Mathematical Thinking and IT' course, iteratively adapted for East African primary mathematics teacher educators. The course adopted theoretical approaches derived from the mathematics, teacher and technology education literatures. It aimed to address the problem of low mathematical functioning by equipping participants for their own work, and also for supporting local collaborative teacher development workshops. The reported study asked, 'What are the affordances and constraints of the adapted course and the available technology for mathematics teacher educator development in this context?'A variety of qualitative tools were used to track the course's impact on the ten mathematics teacher educator participants over six months, as they attempted to transfer course learning to their home professional context. The analysis adopted an ethnographic lens. Outcomes suggested participants with a broad mathematical and pedagogical capacity for change, including critical levels of reflection, made significant progress in their technological, mathematical and mathematics pedagogical expertise. However, teacher educators without such a threshold capacity appeared not able to re-envision practice. Free subjectspecific software was appreciated by all participants, but not yet reliably accessible in these teacher educators' institutional contexts. The reported study evidences the potential for affordable, sustainable, development of many mathematics teacher educators in this context, but further research is needed. Similar courses should take account of local technological and education constraints.
\end{abstract}

@ 2020 Universitas Muhammadiyah Surakarta

\section{Introduction}

Bethell $(\underline{2016})$ argues that for sub-Saharan Africa, mathematical attainment is very low in global terms, severely restricting access to economic and personal thriving in a global $21^{\text {st }}$-century. He argues (p.15, op. cit.) 'the most important group of interventions 
will be those concerned with equipping existing and future teachers of mathematics with the knowledge and competences necessary to help learners acquire deep understanding of mathematical concepts'. Participants in the International Commission on Mathematical Instruction 'capacity network building project' in East Africa concluded (AFRICME 5 conference, August 2018) that a priority for East Africa was mathematical and pedagogical transformation of those responsible for teacher initial and continuing education. Further, emerging evidence suggests both high-quality basic education and productive use of IT are needed to support inclusive human development (Asongu \& Odhiambo, 2019). Any intervention to address those challenges has to be embedded in the local context and take account of local capacity whether it of teachers, teacher educators, technology, or other resources. Affordable, scalable, and sustainable change in mathematics teaching and learning in low resource yet large class contexts is needed, but solutions have to date proved elusive. This paper addresses one such attempt.

We report on design-based research (Anderson \& Shattuck, 2012) addressing the challenge for primary mathematics teacher educators (MTEs) in East Africa. The model is based on a well-established low-cost and research-based structure of proven efficacy for developing teacher capacity in South Africa (e.g., Joubert \& Kenny, 2018), with more than 2000 participants over 34 courses. The new context needed curriculum, participant prior knowledge, and mathematics teacher educator adaptations. The first author and another tutor initially adapted approaches and materials for East African primary mathematics teachers and teacher educators on curriculum and theoretical grounds in 2019, drawing on Halai and Tennant (2016). They did so iteratively as the course progressed, drawing also on the mathematics teacher educator literature indicated below. Halai and Tennant (op. cit.) show that traditional East African mathematics education approaches rely on rote learning. Also, primary teacher grasp of primary mathematics and its teaching is often weak and unconfident. Further, teacher preparation structures typically focus on postsecondary mathematics rather than addressing such issues. Working with MTEs therefore has the potential to disrupt that cycle, as analyzed below.

The study is therefore of an adapted course replication for new target participants (mathematics teacher educators) in a new context (East Africa, rather than South Africa). The second author participated in a parallel part of the course as a secondary MTE: we were, therefore, alert in this study to threats of bias on account of our 'insider' roles: we return to this issue later. The main research question was 'What are the affordances and constraints of the final course as designed, and of the available technology, for mathematics teacher educator development in this context?' Research sub-questions below follow from the theoretical frameworks drawn on.

The paper offers evidence that the analyzed course, drawing on open-source resources and supported remotely, has the potential to seed growth in MTEs' professional capacity across a range of professional functioning, and in new geographical areas. This is subject to amendments appropriate to the curriculum, policy and professional contexts of participants, including their technological context, and also to a minimum level of participants' initial capacity, including for professional reflection. The intervention is in principle both scalable and sustainable, and the approach may be applicable beyond mathematics.

\section{The course and related literature}

In order to contextualize this adapted replication study, it is necessary to understand the background and theoretical framing of the course, the blended (mixed mode) approaches and assessment used, the technology available to participants, and in particular, the theoretical approaches adopted for MTE learning. The focus 'Mathematical 
Thinking and IT' blended learning (face to face/distance) course had first been planned for East African (Kenyan, Rwandan, Tanzanian, and Ugandan) upper primary (and lower secondary) mathematics teachers. It was supplemented in the light of the above recommendations by ten primary MTEs. It began with an intensive residential ten days of face-to-face collaborative learning in a Ugandan university. There followed three months supported distance learning via action research-related activity as participants enacted, evaluated, and further developed the materials and pedagogical approaches for their local context. The course adapted the South African research-based AIMSSEC1 courses, which used materials available online and open access. Further details are given in Table 1.

Table 1

Main events in the primary course

\begin{tabular}{|c|c|c|}
\hline When? & Event & What? \\
\hline $\begin{array}{l}\text { January } \\
2-11, \\
2019\end{array}$ & $\begin{array}{l}\text { Ten-day face-to-face } \\
\text { course for } 10 \\
\text { primary MTEs and } \\
19 \text { primary teachers, } \\
\text { in parallel with a } \\
\text { secondary course }\end{array}$ & $\begin{array}{l}\text { Daily mathematics enrichment shared with secondary participants } \\
\text { and IT sessions. 4-5 daily hours of primary sessions modeling, } \\
\text { discussing, and evaluating active meaning-making approaches to key } \\
\text { areas of the primary curriculum, including developing a range of } \\
\text { minimal cost classroom resources. Focus: deep grasp of primary } \\
\text { mathematics, effective pedagogy for that, and IT for professional } \\
\text { purposes. Repeated experience of 'replay, rehearse, re-envision' } \\
\text { (Horn, 2010) new ways of working with mathematics and its } \\
\text { pedagogy. Daily completion of a reflective journal. }\end{array}$ \\
\hline $\begin{array}{l}\text { January } \\
12,2019\end{array}$ & $\begin{array}{l}\text { End of face-to-face } \\
\text { course test }\end{array}$ & $\begin{array}{l}\text { Written paper focused on primary mathematics and its pedagogy, and } \\
\text { use of basic resources to support that. }\end{array}$ \\
\hline
\end{tabular}

Move home: distance component supported remotely via WhatsApp and email

End of Assignment 1 Plan in detail for active, meaning-making learning in a curriculum February, submission by email area of challenge. Teach the lesson(s) and evaluate the learning 2019 (feedback by email) outcomes, including evidence of your learning and children's work.

End of Assignment $2 \quad$ Plan, run, evidence, and evaluate a local teacher workshop using a March, submissions by email workshop guide from the App. Teach and evaluate one or more 2019 (feedback by email) related lessons, giving evidence of your own and children's learning. End of Assignment 3 Choice of tasks for MTEs: Build on assignment 1 or 2 either a April, submissions by 2019 email(feedback by email) sequence of lessons or a series of teacher workshops and associated teaching or else evaluate and edit for your own context 4-6 teacher workshops from the App around different curriculum areas.

Continued distance support through to at least August 2019

AIMSSEC courses focus on provision for large class and low-resource learning contexts. They aim to support the professional development of participants, and in parallel, equip them to lead local teacher workshops. Additionally, there is a significant role for enhancing competencies for using IT for teaching and learning mathematics: the course is designed to develop all aspects of Mishra and Koehler's (2006) TPACK (technological, pedagogical, and content knowledge) model. Such a focus has become increasingly compelling following the Covid-19 pandemic (e.g., Dreeseni et al., 2020). The East African course was free to participants, funded by an international charity. It recruited two collegebased MTEs from each of Kenya, Tanzania, and Uganda, and two school-based MTEs from each of Rwanda and Uganda. This paper focuses on the learning of the ten primary MTEs (typically educating teachers of 6-14+ year olds), with their key characteristics summarized in Table 2 below. In East Africa, primary teacher initial education is shared between teacher training colleges and schools. Some school-based teacher educators, including those tracked here, also have a local responsibility for later teacher development. Participation in upper primary education in East Africa is now near-universal, but

\footnotetext{
${ }^{1}$ African Institute for Mathematical Sciences School Enrichment Centre
} 
comparatively recently so (Halai \& Tennant, 2016). MTEs are referred to by the pseudonym, without reference to their country of origin, in order to preserve anonymity, given the small numbers involved. In the course, they worked alongside 19 primary teachers of mathematics from across the four countries: 29 primary-focused participants in all. All participants were selected via local education-authority recommendation for their potential as experienced local leaders of teacher development. Course tutors included two primary specialists (one of whom was the first author), two secondary specialists, and one IT for mathematics learning specialist. Phase-specific work was complemented by crossphase workshops focused on participants' mathematics enrichment and IT literacy.

Table 2

MTE study participants, backgrounds, pseudonyms, and available technology

\begin{tabular}{|c|c|c|c|}
\hline Pseudonym & Professional situation & Devices & Institutional hardware \\
\hline Kirabo & $\begin{array}{l}\text { School-based, training college } \\
\text { education }\end{array}$ & Smartphone & 1 computer in school \\
\hline Fredrick & $\begin{array}{l}\text { School-based, training college } \\
\text { education }\end{array}$ & Smartphone & 1 computer in nearby school \\
\hline Tony & $\begin{array}{l}\text { School-based, training college } \\
\text { education }\end{array}$ & $\begin{array}{l}\text { Smartphone, } \\
\text { own laptop }\end{array}$ & No computer in school \\
\hline Ntanbire & $\begin{array}{l}\text { School-based, training college } \\
\text { education }\end{array}$ & $\begin{array}{l}\text { Cellphone (not } \\
\text { smart) }\end{array}$ & 1 computer in school \\
\hline (Fatuma) & $\begin{array}{l}\text { College based. Degree in mathematics } \\
\text { (with education) }\end{array}$ & $\begin{array}{l}\text { Cellphone (not } \\
\text { smart) }\end{array}$ & $\begin{array}{l}1 \text { computer in college: left } \\
\text { course early }\end{array}$ \\
\hline Elizabeth & $\begin{array}{l}\text { College based; no primary teaching } \\
\text { experience. Degree in mathematics } \\
\text { (with education) }\end{array}$ & Smartphone & 1 computer in college \\
\hline David & $\begin{array}{l}\text { College based, training college } \\
\text { education }\end{array}$ & $\begin{array}{l}\text { Smartphone, } \\
\text { own laptop }\end{array}$ & $\begin{array}{l}\text { Small suite of computers } \\
\text { available in college. One } \\
\text { projector, bookable. }\end{array}$ \\
\hline Sulaiman & $\begin{array}{l}\text { College based; no school teaching } \\
\text { experience. Degree in mathematics } \\
\text { (with education) }\end{array}$ & Smartphone & $\begin{array}{l}\text { Small suite of computers } \\
\text { available in college }\end{array}$ \\
\hline Agnes & $\begin{array}{l}\text { College based; no school teaching } \\
\text { experience. Degree in mathematics } \\
\text { (with education) }\end{array}$ & Smartphone & $\begin{array}{l}\text { Small suite of computers } \\
\text { available in college. One } \\
\text { projector, bookable. }\end{array}$ \\
\hline Nakimu & $\begin{array}{l}\text { College based; no primary teaching } \\
\text { experience. Degree in mathematics } \\
\text { (with education) }\end{array}$ & $\begin{array}{l}\text { Smartphone, } \\
\text { own laptop }\end{array}$ & $\begin{array}{l}\text { Several suites of computers } \\
\text { available in college. Projectors } \\
\text { in some teaching rooms }\end{array}$ \\
\hline
\end{tabular}

\section{Course approaches to curriculum and pedagogy}

The course sampled a range of East African primary mathematics content. It addressed affordances of contexts, including analysis of effective low-tech delivery and possible solutions to local technical challenges. In line with the values reflected in regional curriculum documents, tutors' engagements with participants modelled active, meaningmaking approaches to primary mathematics, building sense-making, a deep conceptual grasp, mathematical reasoning, link-making within and beyond mathematics, and mathematical problem-solving. These approaches are well-supported within the global literature (Hodgen, Foster, Marks \& Brown, 2018) - and one element of the course set out to give participants access to such evidence for their own critique and professional knowledge base. Consistent with Hodgen et al. (2018), the pedagogical practices recommended moved away from more traditional classroom roles based on rote learning and memorization of standard examples, but included significant elements of explicit instruction. They are widely valued globally, but aspirational, and to date have not been achieved at scale (e.g., Eurydice, 2011), so the course is ambitious. Ideally, and for added 
confidence, knowledge, skills, and embedding, participants would later also engage in follow-up courses such as those analyzed in Joubert and Kenny (2018). Walter and Briggs (2012), among others, show that effective and sustained teacher (and teacher educator) development is a long process.

\section{Learning mode}

As in Table 1, the course was 'blended', with both face to face and distance learning elements. Entirely face to face learning is prohibitively expensive: teacher development requires sustained input interspersed with the application (Walter \& Briggs, 2012). Equally, entirely distance learning is not effective for the target purposes since it is known that even synchronous webinars for teachers can offer similar opportunities to learn mathematical content but only inferior access to learning new pedagogical approaches (Author1 et al., 2018). We argue both findings are likely to extend to MTEs. For them, pedagogy for both primary learners and primary teachers was a key focus for the East African course.

It was therefore necessary for pedagogical approaches to be very clearly communicated and modelled during the face-to-face phase of the course: this compensated for the limitations of later distance learning for pedagogical change. AIMSSEC course design already incorporated fundamental established facets of effective professional development for teachers. It is longitudinal and active in approach; concrete and classroom-focused; focuses on both subject and subject pedagogical development; intersperses new learning with classroom enactment, exploration, and reflection; informed by external expertise; collaboratively supported; and has scope for mentored contextualization (Walter \& Briggs, 2012).

The design was further characterized as drawing successively on replays, rehearsals, and re-envisioning of practice, as in Horn (2010), and for the focus course, we extended those notions to MTE learning. National 'official' accounts of both curriculum and teacher education proved limited in-depth, detail, and alignment with reported practices 'on the ground.' Actively seeking out participants' accounts of their contextual constraints and opportunities during the course, therefore proved critical to its iterative development.

Participants came with a wide variety of first languages, so the course was conducted in English as the common language available, and the language of instruction for most - but nevertheless, participants' own second or third language. This clearly brings a challenge, mirroring that in many East African classrooms for learners, although participants were encouraged to support one another in local languages where that was helpful.

\section{Technology for professional purposes and the availability of hardware}

Access to internet and online devices was often a significant constraint for the East African primary teacher participants. Distance support was therefore adapted to focus on asynchronous use of downloadable apps and WhatsApp, rather than using online synchronous for a or frequent web access. Participants sometimes (Table 2), but frequently did not, have access to one or more desktop computers in their workplace, with probably intermittent web access - or electricity.

During the residential course, participants had daily structured sessions in a computer room. They engaged hands-on with GeoGebra (free subject-specific software for geometric exploration, graphing or handling data), the free AIMSSEC App offering self-help plans for mathematics teacher collaborative workshops for all phases, sending emails and attachments, writing documents for professional purposes, searching particular internet sites for teaching support and inspiration, and the use of WhatsApp for professional use. 
This range was designed to support future professional functioning. There were also other in-course opportunities when supported computer use was available. At the end of the course, each participant was given a USB containing all materials used.

\section{MTE learning}

MTE learning is known to be complex (Jaworski \& Woods, 2008), and takes place on a number of levels. Classroom teachers in planning have to engage with primary learners' perspectives, as well as a range of subject-related and generic foci (e.g., Ball, Thames \& Phelps, 2008). MTEs have to engage with thinking at those levels, but there is also a metalevel of inducting teachers into such thinking. Most primary teacher education in East Africa currently focuses not on primary mathematics and its pedagogy, but on higher-level mathematics (Halai \& Tennant, 2016). Further, primary MTEs based in colleges are not in general required to have experience of teaching in primary classrooms, so an expectation that they engage with primary classroom level considerations from the point of view of primary teachers and primary learners was very demanding. For school-based MTEs, working with both initial and post-qualification teacher development, the issues are still complex because of the layers involved. The inclusion of MTEs was experimental and smallscale, so they worked collaboratively with practicing classroom teachers. We discuss the affordances and constraints of this approach below.

\section{Course assessment}

Course assessment included formative assessment throughout the initial phase, including self-assessment supported by tutors, via completion of a daily reflective journal. Formal reflective summative assignments are outlined in Table 1; those were also used formatively by tutors. For the first two assignments, MTEs were asked to adapt core teacher assignments for their own professional context, while focusing on the key implications for classroom teachers. All participants needed to evaluate new materials, approaches, and knowledge for their own context, and adapt as appropriate. For MTEs, this included the 'extra layer' of making their learning meaningful for trainee teachers away from the classroom. The assignments, therefore, offered the opportunity to adopt a quasiaction research mode as participants adapted, innovated, and shared their reflections with their tutors. Detailed formative feedback was given on each assignment.

In summary, the course targeted MTE development in several strands: technology capacity for professional use, (primary) mathematics capacity, primary mathematics pedagogy capacity, capacity for mathematics teacher pedagogy, capacity for professional reflection, and capacity for professional innovation. Ultimately, the aim was to enhance the effective functioning of other teachers of mathematics, and of primary learners of mathematics. We, therefore, asked, as sub-questions, 'What are the affordances and constraints of the available technology for supporting primary MTE development in this East African-adapted model? In what ways, and with what limitations, was the course as designed able to support development in each of the areas above? What evidence is there, if any, of positive impact on other teachers or on primary learners?'

\section{Research Methods}

Data were drawn from the primary MTE population of ten, as in Table 3 below: from their journals, in-course working session field notes, and end-of-course test, as well as their assignments and email and WhatsApp communications. The variety of data allowed for active triangulation of emerging findings during the analysis phase. On two occasions during the distance phase, MTEs were sent an internet-based questionnaire, backed up by a Word version. Responses to these were added to the data. Some further rich data around 
transference and post-course contextualization were achieved through audio-recorded, transcribed face-to-face two interviews with one school-based MTE (pseudonym Kirabo). Absence of research funding restricted further such data collection and classroom observations, so the findings reported have limitations as discussed below. Two other MTEs participated only until the last assignment (and second survey): observations and assignment analysis suggest both had struggled to respond to the reflective expectations, including language challenges and the depth of mathematical thinking envisaged, and cited pressure of work for withdrawal. Their data up to their withdrawal are included below since there is much to learn from those who do not complete, as well as those who successfully complete such a course.

Table 3

Data collection

\begin{tabular}{|c|c|c|}
\hline 2019 & Course & Data \\
\hline $\begin{array}{l}3-12 \\
\text { January }\end{array}$ & Face to face element & 10 copies of reflective journals, field notes, 9 test scripts. \\
\hline February & $\begin{array}{l}\text { Assignment } 1 \\
\text { (planning/teaching) }\end{array}$ & Emails, WhatsApp messages, 9 *assignment 1. \\
\hline March & & Reflective e-survey 1: 9 scripts \\
\hline \multirow[t]{2}{*}{ April } & Assignment 2 (workshops) & $\begin{array}{l}\text { Emails, WhatsApp messages, } 8 * \text { assignment } 2 \text {. } \\
\text { Transcribed recording of school-based MTEInterview } 1\end{array}$ \\
\hline & $\begin{array}{l}\text { Assignment } 3 \text { (choice for } \\
\text { MTE's context) }\end{array}$ & Emails, WhatsApp messages, $7^{*}$ assignment 3. \\
\hline $\begin{array}{l}\text { May } \\
\text { June }\end{array}$ & & $\begin{array}{l}\text { Reflective e-survey 2: } 7 \text { scripts } \\
\text { Transcribed recording of school-based MTEInterview2 }\end{array}$ \\
\hline
\end{tabular}

Research surveys and interviews were developed iteratively in a grounded approach (Charmaz, 2006) from January to June 2019, in the light of previous data analysis. In parallel, approaching assignment requirements were also developed in the light of emerging data, responding in particular to the depth of MTE confidence and reflection evidenced. We therefore used end of course testing, and assignments, formatively as well as summatively. Given the genesis of the whole course as an adapted replication and this ongoing development of assignments in the light of the evidence of the nature and degree of participant development, the whole study might be construed as 'educational design research' (McKenney \& Reeves, 2014). This characteristic means further design considerations are intertwined with the analysis of findings reported below.

Survey and interview questions focused on participants' experiences as they embarked on applying course ideas in their home settings; also on their experiences, support, and learning through the three assignments, including their evidence for the impact they claimed on workshop participants and on primary learners. They included a probe around IT-supported learning for the context and the affordances and constraints of locally available technology for professional purposes. We use MTEs' capacity in a field to mean their available resources of related knowledge, skills, and affect (Golding, 2017).

A grounded approach to analysis (Charmaz, 2006) using NVivo, and initial analysis by the research question and sub-questions, resulted in the following emergent themes: technology resources (software and hardware) and related MTE capacity;

- MTEs' own mathematics capacity;

- MTEs' own mathematics pedagogy capacity;

- MTEs' capacity for mathematics teacher pedagogy;

- MTEs' reflective capacity;

- MTEs' capacity for professional innovation; 
- impact on other teachers; and

- impact on primary learners.

Several sub-themes were also grounded in the data: for example, within 'capacity for professional innovation', we placed professional contextual constraints, personal contextual constraints, experience, knowledge, and confidence for a solution-focus, and beliefs that the targeted changes were valuable. Technology capacity included MTEs' technological content knowledge (TCK), technological pedagogic knowledge (TPK), and technological pedagogical content knowledge (TPCK) (Mishra \& Koehler, 2006). Emerging findings were triangulated across data collection events. Those also allowed for tracking of participant responses, learning longitudinally through the two phases of the course, and for the iterative design of surveys and interviews so as to respond to, and probe, those emergent findings. Similarly, analysis of early assignments allowed the design of later tasks that built directly on learning, and challenges, evidenced. Data analysis was, therefore, a key foundation for features of the design.

\section{Limitations/ethical considerations}

The study reported is very much 'insider research' (Mercer, 2007), with its attendant affordances and constraints. Participants were all asked in advance if their anonymized data could be used for research and development purposes, given the novel nature of the course. It was made clear there were no implications for assessments or ongoing professional relationships, and all opted in, with the right to withdraw data at any time to July 2019. They have had the opportunity to validate the public use of that data. However, it is difficult to avoid a power-based bias. In-course data, including reflective journals, and conversations, are necessarily selected - by the participant in what they choose to expose and how they frame that, and by the researcher in the focus adopted and their interpretation of the focus. The effort has been made to ensure quotations used and interpretations made are broadly representative of the range of data, rather than selected for effect. The second author was a (secondary MTE) course participant, so at a rather greater 'distance' (Mercer, 2007) from participants. Interviews were conducted by the second author, with advantages of local presence, of communication in the local language if/when preferred, and of that greater 'distance'.

Once participants returned home, data collection was limited to their accounts, though these were supplemented by video or audio records of teacher workshop and inschool sessions. This was unavoidable given absence of funding for the research and the distances involved. Tutor responses to assignments were framed so as to encourage further discussion and reflection, both tutor-MTE and MTE-colleagues; nevertheless, some elements of activity and reported responses remain subjective, as does participant/author interpretation of data. This is inevitable in work such as this which tries to access participants' lenses so as to better understand what is observed. Importantly, interpretations here have been validated by the relevant MTEs.

Finally, such an in-depth, longitudinal tracking of participants' responses to, and learning from, the course was only manageable because of the small numbers involved. That meant MTEs were able to build quite a deep relationship with the first author (their tutor), so might have felt unusually committed to trying to re-contextualize and re-envisage their learning for their home professional situation. Research activities, such as surveys themselves, might have stimulated further reflection and growth. Inevitably, reporting on the range of responses from the whole cohort of MTEs limits the depth that can be achieved in this paper. However, it was felt important to report on the multiple variations of response evidenced. Such limitations are returned to in the discussion. Below, high-level findings are reported under the research sub-question. 


\section{Results and Discussion}

\section{Technology resources and development of technology-related capacity}

MTEs' access to technological hardware is summarized in Table 2. All participants completed a pre-course survey to ascertain their previous experience in working with technology, as a baseline for planning. Table 4 shows the data for MTEs. By the end of the face to face phase all MTEs were able to independently use all the technological competences listed in Table 4. It was considered important to build awareness of the potential of IT for mathematics learning, even if the modeled extent of that was not yet possible in MTEs' local context. Participants were exposed to experiences covering all of

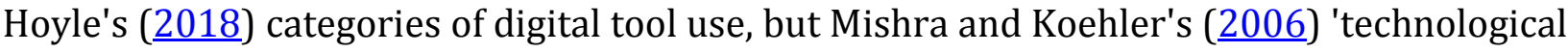
pedagogical content knowledge' is not yet centrally relevant to most participant MTEs because of limited access to hardware. However, MTEs were able to 'replay' their current practice and 'rehearse' new ways of approaching professional tasks with digital support, in Horn's (2010) terms, though they were sometimes challenged to 're-envision' ways of working because of practical access to, and reliability of, the necessary hardware or internet access.

Table 4

Pre-course technology capacity and experience of MTEs

\begin{tabular}{lc}
\hline \multicolumn{1}{c}{ Pre-course technology capacity and experience } & Number of MTEs \\
\hline I am able to use email & 7 \\
I am able to send an attachment with an email & 4 \\
I sometimes use the internet to access teaching ideas or & 3 \\
resources & 8 \\
I use WhatsApp & 0 \\
I use WhatsApp for professional conversations & 0 \\
I sometimes use mathematical software (e.g., statistics, \\
graphing or dynamic geometry software) \\
$\begin{array}{l}\text { I sometimes use a computer for professional purposes } \\
\text { (administrative or teaching/learning) }\end{array}$ \\
\hline
\end{tabular}

In later interviews, Kirabo regularly pointed to her wish to share the joys of geometric exploration using GeoGebra with her teachers, but the nearest set of computers was in a school some distance away. On the occasion she booked that for a workshop, there was no electricity. However, she also pointed to enhanced professional use of the school's one computer, for organizational but also pedagogical purposes, including exploring the internet for resources for other curriculum areas, such as science. The impact of such experiences can, therefore, go beyond the target learning.

As in Table 1, all were required to plan, facilitate, evaluate, and apply at least one AIMSSEC workshop for an assignment. All nine remaining MTEs did so successfully, as evidenced by their accounts, photos, and sometimes video clips. They usually prepared via their USB rather than downloading the most recent content via the live App: data download costs were reported a significant issue for teachers in East Africa. Unfortunately, WhatsApp has recently been targeted by some East African governments for additional taxation, presumably because it is seen as a social media tool, and so an optional extra, rather than a conduit for professional interchange. However, in the distance phase onwards, as in So ( $\underline{2016})$, most MTEs made much more use of the WhatsApp group set up, than of email, and indeed, were far more responsive to tutor communications via WhatsApp.

In summary, data showed a significant impact on the capacity for using technology for professional purposes, over at least four months: use of digital resources on the App, and of email and WhatsApp for communication and reflection. Some MTEs also reported greater 
use of IT for their own or colleagues' use beyond their mathematics teaching, including for organization and administration. All diaries showed growth in appreciation of the potential of subject-specific software for teaching and learning, and of online resources for expanding MTEs' own, and their learners', knowledge. At present, however, internet access for these MTEs is such that in Survey 2 only three referred to post-course internet searches or downloads, whereas all reported use of the USB content beyond the mandated assignments.

\section{Development of mathematics capacity}

All participants were locally considered experts in mathematics education, as required for enrolment on the course as an MTE. However, in-course probing showed some key primary mathematical concepts were poorly-grasped. Early course interactions aimed to expose particular areas of challenge. These included primary pre-algebra and algebra, probability, and use of statistics, though core concepts such as fractions, decimals, and percentages also emerged as areas of challenge. In-course primary sessions were edited to ensure addressing and deepening of these, including through modeling effective primary pedagogy as in Hodgen et al. (2018). The end of course test focused on the combination of focus primary mathematics knowledge and its pedagogy, and here the MTEs scored a mean of $86 \%$ (SD 9\%), as compared with a mean of $68 \%$ (SD 25\%) for the whole primary (teachers plus MTEs) group of 29. Mathematically, then, and in terms of being able to apply and reflect on pedagogical thinking, they were relatively confident within the primary group.

All ten claimed in survey 1 and/or in journals to have significantly developed their understanding of primary mathematics and gave specific examples through the face to face course. Their confidence to probe the associated meaning-making and link-making, both within and beyond mathematics, was also reported to have increased. Assignments, though, also exposed continuing limitations to that, for example, equating one-fifth with $5 \%$. There is a tension between the study of post-primary (and often post-secondary) mathematics that is often the focus of primary teacher or teacher educator preparation, and the deep knowledge of primary mathematics that the literature suggests is what is needed for effective teaching (e.g., Adler \& Davis, 2006) - or primary teacher education. What we see, then, is a confidence in having made progress in key mathematics capabilities, but a need for further long-term development of that. At least four MTEs identified further mathematics learning as they adapted and applied course ideas in their local context, both through their own professional classroom situation and facilitating local teacher workshops. These four were, in general, particularly reflective MTEs, although not initially those with the strongest conceptual grasp of primary mathematics. That reflection was observed through assignments to be critical to continuing to build a variety of professional knowledge on initial in-course learning.

\section{Development of mathematics pedagogy capacity}

For all primary MTEs, the course featured substantially novel approaches to pedagogy, focusing as it did on active learning for meaning-making within a large class and low resource context. The whole primary group, at 29 participants, was not comparable with the sizes most MTEs encountered in their own school or college (often 100 or more, and for some in colleges, over 200), though on occasion they worked with the 30 lower secondary teachers to make a class of 60 . Nevertheless, after initial scepticism about the availability of resources and adaptation to large classes, participants were observed to rapidly adopt and record a reflection on adaptations so as to transfer to their professional contexts the learning opportunities they were themselves experiencing: 
We now have good ways to make the data meaningful to our learners and it will work very well if I take them outside and use chalk. I did not know what the pie charts meant, but the way we have experienced will be even better (than on the course) with a large class (Ntanbire, journal);

The number line and the hundred square are very good ways of thinking and if I make two of them, then all my learners will be able to see (Agnes, journal).

Such reflection and adaptation continued in a variety of depths into assignment work, e.g., Kirabo generalizing 'people maths' approaches to form a 'human abacus' with her learners. MTEs all expressed personal enjoyment and mathematical elucidation, via the active approaches taken, and through the ten days face to face claimed to develop the confidence to spontaneously share ideas for further localized development. Here, the 'modelling' approach taken by tutors meant participants directly experienced mathematics in ways intended to be used in classrooms. The move from 'replaying' home learning situations to 'rehearsing' alternatives aligned with new experiences was then wellsupported, and the more experienced MTEs were during the course often able also to 'reenvision' context-specific adaptations of those, in Horn's (2010) terms. Once they were back in their local contexts, all MTEs reported enhanced confidence to probe, to explore, and to take risks in their respective classrooms, as they began to prepare lessons in more depth and deliberation, drawing too on their own in-course experiences:

I have spent some time preparing for this lesson and so I was more confident that if the pupils ask, I can answer. But I did not know that you can play games to help teach about place value, and my pupils and I are having very much fun and so they want to learn and they ask when can we play some more games and can we make up one that will make me get stuck. I think it is a good approach (Tony, Assignment 1).

However, local classroom enactment and everyday pressures brought a variety of challenges to the time and commitment needed to maintain such approaches. Submitted assignments showed a variety of depths of reflection and of the grasp of key ideas MTEs had worked with during the course. Assignments and surveys showed that two collegebased MTEs, in particular, found it difficult to re-envision their teaching in ways which were consistent with those promoted, or to reflect in-depth on their local enactments, once they were in their home context. Neither completed Assignment 3.

\section{Development of capacity for mathematics teacher pedagogy:}

As analyzed above, MTEs have an additional 'layer' to their work that is focused on teaching pre- or in-service teachers. For this course, tutors incorporated into sessions opportunities for MTEs to rehearse, and reflect towards re-envisioning, their practice. They did this by using teacher 'micro-teaching' episodes where MTEs planned and led primary teachers in the group in rehearsals of new pedagogies. MTEs then rehearsed constructive feedback and co-re-envisioning of practice. From early on, reflective journals and insession talk showed college-based MTEs were challenged to re-envisage for their teacher education role approaches they personally claimed to experience as, for example, 'inspirational and concept-changing' (Elizabeth, journal, day 5). We note three had fewer than five years' experience in their role. However, those who persisted chose to complete assignments via a comparatively challenging, verging on the subversive, role that engaged trainee teachers in non-standard material, using approaches non-standard in East African classrooms, even though they were offered alternatives that would instead have meant working with local teachers and local primary classrooms:

Given my audience, where students don't study primary school mathematics that they are supposed to teach after graduating, I struggled convincing them why we had to use primary school mathematics activities and the switch in pedagogy. It was a struggle but worthwhile (Nakimu, survey).

For a college-based MTE's professional situation, adaptation was in a demanding situation where the organization and structure were typically not designed to support 
active, meaning-making experiences that would model beginner teachers' opportunities in primary classrooms. Assignment reflections show only two of the five college-based MTEs who remained on course, Agnes and Nakimu, were able to re-envisage their teaching practice to consistently accommodate practices that deeply reflected course approaches. One did so to some extent, and the other two failed to complete the third assignment. Three of the four school-based MTEs, in contrast, appeared to thrive on the assignments. They developed clearly differentiated approaches to working with teachers instead of children, transferring approaches to planning for learning, and to active, meaning-making collaborative tasks, and developing those between assignments 2 and 3 . Kirabo, for example, worked with an in-school senior colleague who had also been on the course to prepare a series of four after-school teacher workshops that saw full attendance by seventeen local teachers. They targeted areas of the curriculum that participants had deemed most problematic: 'They (local teachers) have been inspired, they kept choosing to come back and now they want more. They say they are now enjoying their maths teaching so much.' (Kirabo, interview 2).

The fourth school-based MTE had comparatively weak mathematics knowledge, as evidenced by confused in-session participation and written test, assignments, and survey responses. Assignments showed he struggled to be confident to 'let go' of familiar didactic approaches, especially with other teachers, though also with his own class. His accounts suggest he had neither the deep mathematical knowledge nor the confidence to fully adopt the approaches promoted on the course and via the AIMSSEC App. The course recruited only those already recognized as influential in local mathematics teaching, but this suggests that in some areas, such educators are not themselves well-equipped for further demanding professional development.

\section{MTEs' reflective capacity}

The depth of reflection expected during both phases of the course appeared to be demanding for MTEs: 'I did not think you wanted us to decide where it (the approach) would not work. It is easier to be told how to teach the ideas' (David, journal, day 4). Within assignments, there were elements that reflected course tutor vocabulary quite closely (as a way of supporting the expression of reflection), focused on practical rather than pedagogical challenges, and stopped at observations of trainee teacher responses without also explicitly making the link to common primary learner misconceptions:

Teaching through workshops is very involving, especially on the side of preparations. However the benefits seem to override all the hassles. The activities required the use [of] visual, auditory, and kinaesthetic skills.....Learners were sure about the line of symmetry in some of the quadrilaterals but in some instances ..it wasn't there, examples [were] with rectangles, rhombus and parallelograms. (Sulaiman, Assignment 2)

Some of these apparent limitations in reflection might well have been due to challenges with language. However, there was also a spontaneous reflection on wider issues:

The cross-cutting issue that will be addressed is inclusive education and gender balance where all learners even those with disabilities and girls participate actively; critical thinking through reasoning to the steps followed in the questions; developing lifelong learning through solving problems of daily life; communication and cooperation are developed through discussions in group (Ntanbire, Assignment 3).

MTEs, then, varied in their capacity for deep professional reflection. The two MTEs who did not complete the last assignment both struggled to develop depth in their reflection. One had apparently fluent English; for the other, language might have been a barrier, although in-group developing reflection was usually communicated to her in Swahili. 


\section{Capacity for professional innovation}

Capacity for the transformation of practice appears to have been impacted by a combination of MTE experience, knowledge, reflective capacity, and confidence - and MTEs' beliefs, including that the targeted changes were valuable. Of these, mathematics knowledge at the beginning of the course appeared to play only a small part: for example, Karibu said she 'struggled with some ideas in mathematics and that was borne out in face to face group work, but she engaged proactively with mathematical and pedagogical ideas she met, and evidence from her post-course enactment suggests effective transfer to her home professional situation. MTE accounts of their planned changes in practice sometimes quoted from tutors:

(When you returned to your workplace in January, which aspects of your course learning did you try to prioritize putting into practice?) Shifting from planning for teaching to planning for learning! Reducing on talking by a teacher and encouraging learners in more activities (David, survey 1);

Other MTEs, though, were much more specific:

a) The practical activities in introducing topics; b) Having the six mathematics major displays in the classroom, i.e., 100 number grid, the timetable, 100 number line, clock face, calendar, a chart showing shapes, etc.; c) people maths is also working well and I have made some new people maths activities (Fredrick, survey 1).

Of course, there is no opportunity to probe survey responses, so the variation within this might or might not reflect sizeable differences on the ground. This is a clear limitation of the lack of local observation available for post-course. Where assignments evidenced ambitious classroom or workshop change, MTEs had made significant use of a range of support available: 'colleagues in my workplace; WhatsApp group, course tutor distance support...' (Ntanbire, survey 2). Such MTEs also tended to give non-standard responses when asked in survey 2 about the impact on them personally:

It has made me reflect more critically on my practices and I am practicing doing things differently. In the workshop, I were [was] in a position to handle a topic I had not before and I have helped the teachers to believe that we can handle the subject better (Karibu);

Enjoying lessons by allowing learners to interact freely during lessons (Fredrick);

I have become more confident in my pedagogy and proud of the products I see. I have learned to plan better and also involve learners in their learning (Nakimu);

Made learning and teaching enjoyable and authentic. I thought it was too hard to enjoy maths with large classes, but the approaches work for my classes of about 85 children (Ntanbire).

Overall, all MTEs who completed the last assignment offered evidence that they were beginning to embed at least some of the practices promoted during face to face, though with variable depth and ambition. This appeared particularly challenging for college-based MTEs, who had to engage with deeply transformational re-envisaging of practice in order to achieve that.

\section{Impact on other teachers and on primary learners}

Eight of the nine MTEs who completed assignments were able to evidence significant positive impact on either primary learners or trainee teachers in their context, and seven of them on other local practicing teachers also:

It has changed the attitude of my teachers to maths: they are interested and chase me to borrow resources we have made, and they talk enthusiastically about it... And the children have caught that: they are trying out different methods and getting very excited about maths, now its hands-on practical and inquiry-based. Children are becoming very inquisitive and spending time in the library investigating ideas (Kirabo, interview 2);

Teaching mathematics has become more simple and the learners have picked interest in the subject, they now have confidence in it (David, survey 2); 
They (local teachers) got new ways of looking at content since they thought that maths isn't practical (Fredrick, survey 2);

The teacher trainees feel very excited about the paradigm shift. They say they are ready to implement such practices in their forthcoming school practice in June 2019 (Nakimu, survey 2).

Kirabo also talked explicitly about learner attainment:

I've been marking the related assignments and I'm seeing them improving so much. They're getting excited and they are achieving excellent results. And they know they are getting better, so they feel great. (Kirabo, interview 1).

For those based in teacher training colleges, working with local teachers was a significant achievement, given their usual very limited professional interaction with serving teachers, but was also reported to be helpful to their trainees:

I organized the workshop for local teachers, and they really responded well to it, and they kept adding new ideas for their classrooms. So when I adapted the approach in the AIMSSEC workshop for my trainees, they know it's not on the syllabus and they were resistant at first, but then they were so enthusiastic about how much it will help them when they are next in school (Agnes, Assignment 3).

\section{Conclusion}

This paper analyses the potential of an established teacher development course to transfer to new geographical contexts, suitably adapted for local curriculum and constraints, and to provide for the development of MTEs, who are highly influential on emerging teachers. Importantly, key materials for both phases of the course are available open access, although the overall success depends on experienced and widelyknowledgeable tutors. The adaptations suggest a combination of college-based and schoolbased MTEs with practicing locally-influential teachers is particularly fruitful. There are also advantages to the local pairing of participation to support embedding.

The MTEs who evidenced the most embedded change to their practice also showed a basic subject and pedagogical knowledge, deep professional reflection, and a solutionfocused, confident commitment to making the targeted change. Such MTEs appeared then to be able to make significant progress in their technological, mathematical, and mathematics pedagogical expertise and adapt, embed, and further develop that in their practice, at least in the short- and medium-term. Reports suggest they were also able to positively influence the mathematical and pedagogical capacity of other teachers and to impact primary pupil learning - of mathematics and of positive affect. The course analyzed also appeared sufficient to equip professionally confident MTEs with technological tools to access a range of materials for their own or (college or school) students' learning via the digital access available to them. It supported moving to professional interchanges and development at a range of levels and granularities via smartphones, occasional access to a computer or laptop, a variety of Apps, social media groups, and organizational/executive software. Easy access to appropriate software and hardware, and connectivity, though, remains a challenge for many in East Africa, and it is important such a course recognizes local constraints.

The indications are that learning gains are sustainable: for example, private correspondence shows one participant in Spring 2020 running district-wide workshops for teachers based on the course materials and approaches. In principle, comparable adaptations should make the course equally impactful elsewhere.

Research on the larger-scale provision, complemented by a more in-depth analysis of individual learning gains, is needed to more securely establish the viability and impact of the approach - on MTEs, teachers, and learners. In particular, any such research should 
include greater evidencing of the impact of the key target for such development - namely, the primary learner in the classroom.

\section{Acknowledgment}

The University of London Centre for Distance Education part-funded this research.

\section{Bibliography}

Adler, J., \& Davis, Z. (2006). Opening another black box: Researching mathematics for teaching in teacher education mathematics knowledge. Journal for Research in Mathematics Education, 37(4), 270- 296. https://doi.org/10.2307/30034851

Anderson, T., \& Shattuck, J. (2012). Design-based research: a decade of progress in education research? Educational Researcher, 41(1), 16 - 25. https://doi.org/10.3102/0013189X11428813

Asongu, S. \&Odhiambo, N. (2019). Basic formal education quality, information technology, and inclusive human development in sub-Saharan Africa. Sustainable Development, 27(3), 419-428. https://doi.org/10.1002/sd.1914

Golding, J. (2017). Mathematics teacher capacity for change. Oxford Review of Education, 43(4), 502-517. https://doi.org/10.1080/03054985.2017.1331846

Golding, J., \& Bretscher, N. (2018). Developing pedagogies for a synchronous online course on teaching pre-university mathematics. Teaching Mathematics and its Applications, 37(2), 98-112. https://doi.org/10.1093/teamat/hry010

Ball, D. L., Thames, M. H., \& Phelps, G. (2008). Content knowledge for teaching: what makes it special? Journal of Teacher Education, 59 (5), 389- 407. https://doi.org/10.1177/0022487108324554

Bethell, G. (2016). Mathematics education in Sub-Saharan Africa: Status, Challenges, and Opportunities. World Bank. Report No: ACS19117. Retrieved from http://documents1.worldbank.org/curated/en/538251476977591230/pdf/ACS191 17-V2-Version-2-Full-report-final-P152990-PUBLIC.pdf

Charmaz, K. (2006). Constructing grounded theory. Thousand Oaks: Sage Publications.

Dreeseni, T., Akseer, S., Brossard, M., Dewan, P., Giraldo, J-P., Kamei, A., Mizunoya, S. \& Ortiz, J. (2020). Promising practices for equitable remote learning. Florence: UNICEF. Retrieved from https://www.unicef-irc.org/publications/pdf/IRB\%202020-10.pdf

Eurydice.(2011). Mathematics education in Europe: Common challenges and national policies. EACEA. Retrieved from https://op.europa.eu/en/publication-detail/Lpublication/3532f22d-eea2-4bb2-941b-959ddec61810/language-en

Halai, A., \& Tennant, G. (Eds.) (2016). Mathematics education in East Africa: Towards harmonisation and enhancement of education quality. Springer: Dordrecht. Retrieved from: https://link.springer.com/book/10.1007/978-3-319-27258-0

Hodgen, J., Foster, C., Marks, R., \& Brown, M. (2018). Improving mathematics in key stages two and three: evidence review. London: Education Endowment Foundation. Retrieved from

https://educationendowmentfoundation.org.uk/evidencesummaries/evidencereviews/improving-mathematics-in-key-stages-two-and-three/

Horn, I. S. (2010). Teaching replays, teaching rehearsals, and re-visions of practice. Teachers College Record, 112(1), 225-259.

Hoyles, C. (2018). Transforming the mathematical practices of learners and teachers through digital technology. Research in Mathematics Education, 20(3), 209- 228. https://doi.org/10.1080/14794802.2018.1484799

Jaworski, B., \& Wood, T. (Eds.) (2008). The mathematics MTE as a developing professional. Sense Publishers: Rotterdam. 
Joubert, M., \& Kenny, S. (2018). Exploring the perspectives of participants in two mathematics professional development courses in South Africa. African Journal of Research in Mathematics, Science and Technology Education, 22(3), 319- 328. https://doi.org/10.1080/18117295.2018.1525093

McKenney, S., \& Reeves, T.C. (2014). Educational design research. In Spector J., Merrill M., Elen J., Bishop M. (Eds.) Handbook of Research on Educational Communications and Technology. Springer, New York, NY, pp.131-140.

Mercer, J. (2007). The challenges of insider research in educational institutions: Wielding a double-edged sword and resolving delicate dilemmas. Oxford Review of Education, 33(1), 1-17. https://doi.org/10.1080/03054980601094651

Mishra, P. \& Koehler, M. J. (2006). Technological pedagogical content knowledge: A framework for teacher knowledge. Teachers College Record, 108(6), 1017- 1054. https://doi.org/10.1111/j.1467-9620.2006.00684.x

So, S. (2016). Mobile instant messaging support for teaching and learning in higher education. Internet and Higher Education, 31(1), 32- 42. https://doi.org/10.1016/j.iheduc.2016.06.001

Walter, C., \& Briggs, J. (2012). What professional development makes the most difference to teachers? Oxford: Oxford University Press. 